\title{
Extraction optimization and characterization of polysaccharide antioxidants from Pinellia ternata (Thunb) Breit rhizome
}

\author{
Xuelin Mo ${ }^{1}$, Yujie Liu ${ }^{1}$, Tao $\mathrm{Li}^{1}$, Wei Peng ${ }^{1}$, Meibian $\mathrm{Hu}^{1}$ and Chunjie $\mathrm{Wu}^{1,2 \star}$ \\ ${ }^{1}$ College of Pharmacy, Chengdu University of Traditional Chinese Medicine, ${ }^{2}$ Key Research Laboratory of Traditional Chinese \\ Medicine Processing Technology, State Administration of Traditional Chinese Medicine of People's Republic of China, \\ Chengdu 611137, PR China
}

*For correspondence: Email: wucjcdtcm@163.com; Tel/Fax: +86-028-61801001

\begin{abstract}
Purpose: To investigate the optimum extraction conditions of polysaccharides from Pinellia Rhizoma (PRP) and their antioxidant activities.

Methods: Response surface methodology (RSM) was applied to optimize the water extraction conditions of PRP by Box-Benhnken design (BBD). A high performance liquid chromatography (HPLC) method was performed for determining the monosaccharide composition, while a high performance gel permeation chromatography (HPGPC) method was established for determining the molecular weight distribution of PRP. In addition, scavenging DPPH and superoxide anion radical scavenging assays were used to evaluate the antioxidant activities of PRP.

Results: As a result, the optimum extraction conditions of PRP were as follows: extraction time, 103 min; solid-liquid ratio, $24 \mathrm{~g} / \mathrm{mL}$; and extraction no., 3. Under these conditions, the maximum extraction yield of PRP was $2.47 \%$, which matched the optimum value (2.55\%) predicted by RSM. The results of HPLC analysis suggest that the monosaccharide composition of PRP was mannose (Man), galactose acid (Gal acid), galactose (Gal), glucose (Glc), and arabinose (Ara) in molar ratios of 5.76:2.20:2.64:4.57:1, respectively, and the molecular weight ranged from 13592 to 445065. Furthermore, PRP showed marked antioxidant activities with the highest DPPH free radical scavenging rate of $71.5 \%$ and $O^{2-}$ free radical scavenging rate of $87.5 \%$ at a concentration of $10 \mathrm{mg} / \mathrm{mL}$.

Conclusion: RSM is a rapid and effective statistical technique for optimizing conditions for PRP extraction. Furthermore, PRP is a potential natural source of antioxidants.
\end{abstract}

Keywords: Pinellia rhizoma, Polysaccharides Optimization extraction, Monosaccharide composition, Antioxidant activity

Tropical Journal of Pharmaceutical Research is indexed by Science Citation Index (SciSearch), Scopus, International Pharmaceutical Abstract, Chemical Abstracts, Embase, Index Copernicus, EBSCO, African Index Medicus, JournalSeek, Journal Citation Reports/Science Edition, Directory of Open Access Journals (DOAJ), African Journal Online, Bioline International, Open-J-Gate and Pharmacy Abstracts

\section{INTRODUCTION}

Pinellia ternata (Thunb.) Breit. is an important medicinal plant from the Araceae family, and is widely distributed in Anhui, Sichuan and Hubei provinces of China. Its Rhizoma (PR) has been used in Traditional Chinese Medicines (TCMs) for its antiemetic, antitussive, anti-tumor, antimicrobial, anti-obesity, anticonvulsant activities and other therapeutic efficacies [1-6]. Studies have shown that the main constituents of PR are proteins, alkaloids, polysaccharides and organic acids [7-10]. Recently, it has been reported that an increasing number of polysaccharides from natural sources have excellent antioxidant activities [11]. 
Polysaccharides are important constituents of $\mathrm{PR}$, which have been reported to possess significant anti-tumor effects [12-14]. However, little information is available in the literatures regarding the antioxidant effect of PRP.

The aim of the present study was to apply RSM to optimize the extraction conditions of PRP, furthermore, monosaccharide composition and molecular weight of PRP were investigated in order to characterize the structure of PRP.

\section{EXPERIMENTAL}

\section{Chemicals and reagents}

Standard monosaccharides (Mannose, Glucose, Galactose, Galactose acid, and Arabinose), and dextrans of different molecular weights were obtained from National Institute for the Control of Pharmaceutical and Biological Products (Beijing, China); Phenol, concentrated sulfuric acid $\left(\mathrm{H}_{2} \mathrm{SO}_{4}\right)$ and 3-Methyl-1-phenyl-2-pyrazolin-5one (PMP), trifluoroacetic acids (TFA) were purchased from the Sino Pharm chemical reagents (Shanghai, China); 1,1-diphenyl-2picrylhydrazyl (DPPH), Vitamin C (Vc) and 1,2,3-trihydroxy-benzene were purchased from Sigma Co (St. Louis, MO, USA). All other solvents and chemical reagents used in this study were of analytical reagent grade.

\section{Extraction procedure}

Pinellia Rhizoma was purchased from Sichuan New Lotus Chinese Herbal Pieces Co., Ltd. (Chengdu, China) in April, 2016 (batch no. D1601137), and was authenticated by Professor Chun-Jie Wu (College of Pharmacy, Chengdu University of Traditional Chinese Medicine). A voucher specimen (no. sPR-20160715) was deposited in the herbarium of College of Pharmacy, Chengdu University of Traditional Chinese Medicine (Chengdu, China).

Crude polysaccharide extraction was carried out using a method described previously [15] with some modifications. The Pinellia Rhizoma (PR) powder was extracted with $95 \%$ ethanol (1:3, $\mathrm{w} / \mathrm{v}$ ) for $2 \mathrm{~h}$ by reflux. After filtration, the residue was air-dried and re-extracted twice with distilled water by reflux. The obtained solutions were filtered by filter paper, and the filtrate was concentrated at $50{ }^{\circ} \mathrm{C}$ under vacuum. Amylase $(20 \mathrm{~mL})$ was added to remove the starch, and the excess amylase was removed by boiling for 5 min. After centrifuging at $5000 \mathrm{rpm}$ for $10 \mathrm{~min}, 95$ $\%$ ethanol was added to the supernatant to make the ethanol content of $80 \%(\mathrm{v} / \mathrm{v})$, and then stored overnight at $4{ }^{\circ} \mathrm{C}$. After centrifugation (5000 rpm, $10 \mathrm{~min}$ ), the precipitates were collected and washed thrice with anhydrous ethanol, acetone and aether, and finally dried at $50{ }^{\circ} \mathrm{C}$ to obtain the PRP. The phenol-sulfuric acid method [16] was used to determine the polysaccharide content of PRP. The percentage extraction yield (\%) of PRP was calculated by using the following equation (Eq 1).

Yield $(\%)=\left(\mathrm{C}_{1} / \mathrm{C}_{0}\right) 100$

where $\mathrm{C}_{0}$ is the weight of raw material and $\mathrm{C}_{1}$ is the weight of crude polysaccharide.

\section{Optimization of PRP extraction}

Three major influence factors affecting the extraction yield of PRP were selected: extraction time (A, min); number of extraction $(B)$ and solidliquid ratio $(C, g / m L)$. These three factors were set at three different levels coded $-1,0,+1$ to represent the low, medium and high grade, respectively. The yield of polysaccharides was used as the response value, and the code of the levels and factors are shown in Table 1.

\section{Monosaccharide composition analysis}

The monosaccharide composition of PRP sample was determined by HPLC with precolumn derivatization. The hydrolysis of polysaccharides was performed using previously described methods [17]. PRP (20 mg) was hydrolyzed in TFA $(2 \mathrm{M}, 5 \mathrm{~mL})$ for $5 \mathrm{~h}$ at $110{ }^{\circ} \mathrm{C}$ in a sealed test tube. The hydrolysate was cooled to room temperature, and then the supernatant was obtained after centrifugation (5000 rpm, $15 \mathrm{~min}$ ) and dried at $50{ }^{\circ} \mathrm{C}$ using a rotary evaporator. The residue was washed with methanol three times to remove the TFA, and then dissolved in $2 \mathrm{~mL}$ distilled water.

Table 1: Factors and levels of RSM experiments

\begin{tabular}{lllll}
\hline \multirow{2}{*}{ Symbol } & Independent & \multicolumn{2}{l}{ Code level } & \\
\cline { 3 - 5 } & variable & -1 & 0 & 1 \\
\hline $\mathrm{A}$ & Extraction time $(\mathrm{min})$ & 90 & 120 & 150 \\
$\mathrm{~B}$ & Number of extraction & 1 & 2 & 3 \\
$\mathrm{C}$ & Solid-liquid ratio $(\mathrm{g} / \mathrm{mL})$ & 10 & 20 & 30 \\
\hline
\end{tabular}


The pre-column monosaccharide derivatives were prepared using PMP reagents according to a previous method [18]. Man, Gal acid, Glu, Gal, and Ara were used as monosaccharide standards, and dissolved in distilled water (2 $\mathrm{mM})$. PMP solution (0.5 M, $0.2 \mathrm{~mL})$ and $\mathrm{NaOH}$ solution $(0.3 \mathrm{M}, 0.2 \mathrm{~mL})$ were added into the hydrolyzed polysaccharide sample $(0.2 \mathrm{~mL})$ and monosaccharide standard solutions $(2 \mathrm{mM})$, and then maintained in a water bath at $70{ }^{\circ} \mathrm{C}$ for 60 min. After incubation, the mixture was then completely neutralized by adding $0.2 \mathrm{~mL} \mathrm{HCl}(0.3$ M). Subsequently, $1 \mathrm{~mL}$ trichloromethane was added, and mixed thoroughly by vortexing. The organic phase was carefully discarded and the aqueous phase was diluted to $5 \mathrm{~mL}$ with distilled water.

The monosaccharide analysis was performed on a CAPCELL PAK MG II S5 C18 column $(4.6 \mathrm{~mm}$ $\times 250 \mathrm{~mm}, 5 \mu \mathrm{m}$ ) by Agilent $1260 \mathrm{HPLC}$ system (Agilent, USA). The mobile phase was composed of $0.05 \mathrm{M}$ phosphate buffer $(\mathrm{pH}=6.8)$ and acetonitrile $(82: 18, \mathrm{v} / \mathrm{v})$, the flow rate was 0.8 $\mathrm{mL} / \mathrm{min}$, and the injection volume was $5 \mathrm{uL}$. The column temperature was maintained at $35^{\circ} \mathrm{C}$, and the detection wavelength at $245 \mathrm{~nm}$.

\section{Molecular weight distribution test}

HPGPC was used to determine the molecular weight $\left(\mathrm{M}_{\mathrm{W}}\right)$ distribution of polysaccharides sample according to a previous report [20]. A series of dextran with different molecular weights, viz, $1.26 \times 10^{4}, 7.38 \times 10^{4}, 1.10 \times 10^{5}$, $2.89 \times 10^{5}$, and $4.96 \times 10^{5} \mathrm{~g} / \mathrm{mol}$ were used to construct a calibration curve. PRP $(20 \mathrm{mg})$ was dissolved in distilled water $(2 \mathrm{~mL})$, and centrifuged (10,000 rpm, $5 \mathrm{~min})$. The supernatant was filtered through a $0.22 \mathrm{~mm}$ filter before injection. The TSK-Gel G4000 SW $\mathrm{XL}(7.8 \mathrm{~mm} \times$ $30 \mathrm{~cm}, 8 \mu \mathrm{m}$ ) column was used to separate the sample at $40{ }^{\circ} \mathrm{C}$ with distilled water as mobile phase at a flow rate of $0.8 \mathrm{~mL} / \mathrm{min}$. The sample was detected by Alltech 2000 ES evaporative light-scattering detector; the injection volume was $20 \mathrm{uL}$. The data were analyzed by EZChrom Elite software (Agilent Technology, CA).

\section{DPPH radical scavenging assay}

The DPPH radical scavenging test was performed by the method reported by Bartolomeuws et al [21]. Different concentrations of $\operatorname{PRP}(1,2,4,6,8,10 \mathrm{mg} / \mathrm{mL})$ were prepared, and $2 \mathrm{~mL}$ of DPPH solution $(0.04 \mathrm{mM})$ were added and mixed. The solutions kept in the dark at room temperature for $30 \mathrm{~min}$, and then measured the absorption at $517 \mathrm{~nm}$. Vitamin C (Vc) was used as positive control. DPPH free radical scavenging rate $(D)$ of the sample was computed as in Eq 2.

$D(\%)=\left\{1-\left(A_{1}-A_{2}\right) / A_{0}\right\} 100$

where $A_{0}$ is the absorbance of the control (distilled water), $A_{1}$ is the absorbance of the sample, and $A_{2}$ is the absorbance of the sample only (ethanol instead of DPPH solution).

\section{Superoxide anion $\left(\mathrm{O}^{2-}\right)$ radical scavenging assay}

The $\mathrm{O}^{2}$ - radical scavenging test was carried out according to a previous report by Wang et al [22]. Sample solutions $(1 \mathrm{~mL})$ of different concentrations of PRP $(1,2,4,6,8,10 \mathrm{mg} / \mathrm{mL})$ were prepared and $4.5 \mathrm{~mL}$ Tris- $\mathrm{HCl}$ buffer (50 $\mathrm{mM}, \mathrm{pH}=8.2$ ) were added. After incubation at 25 ${ }^{\circ} \mathrm{C}$ for $10 \mathrm{~min}, 0.1 \mathrm{~mL}$ pyrogallol $(25 \mathrm{mM})$ were added and mixed. Concentrated hydrochloric acid $(0.5 \mathrm{~mL})$ was added to stop the reaction. Finally, the absorption was measured at $320 \mathrm{~nm}$. $\mathrm{Vc}$ was used as positive control. $\mathrm{O}^{2-}$ scavenging rate $(S)$ of the sample was calculated using Eq 3.

$S(\%)=\left\{1-\left(B_{1}-B_{2}\right) / B_{0}\right\} 100$

where $B_{0}$ is the absorbance of the control (distilled water), $B_{1}$ is the absorbance of the sample, and $B_{2}$ is the absorbance of the sample only (distilled water instead of pyrogallol solution).

\section{Statistical analysis}

The results were analyzed with SPSS 17.0 software (SPSS Inc, Chicago, IL, USA). The experimental data from RSM was analyzed using version 8.0.5 Design-Expert software (Stat-Ease Inc, Minneapolis, MN, USA). Analysis of variance (ANOVA) was used to analyze the results, and $p$ $<0.05$ was considered statistically significant.

\section{RESULTS}

\section{Optimized extraction conditions}

RSM data based on BBD of PRP extraction are shown in Table 2. The entire design consisted of 17 experiments based on BBD, and all the experiments were performed in random order.

The regression equation (Eq 4) was obtained by quadratic polynomial using Design-expert 8.05 b software.

$Y=2.47+0.078 \mathrm{~A}+0.12 \mathrm{~B}+0.056 \mathrm{C}+0.067 \mathrm{AB}$

$+0.013 A C-0.005 B C-0.15 A^{2}-0.10 B^{2}-$ $0.068 C^{2}$ 
Table 2: Experimental points of BBD and the experimental data

\begin{tabular}{lllll}
\hline Run & A & B & C & $\begin{array}{l}\text { Yield } \\
(\%, Y)\end{array}$ \\
\hline 1 & 0 & 0 & 0 & 2.52 \\
2 & 0 & -1 & 1 & 2.22 \\
3 & 1 & -1 & 0 & 2.11 \\
4 & 0 & 1 & -1 & 2.39 \\
5 & -1 & 0 & -1 & 2.12 \\
6 & -1 & -1 & 0 & 2.09 \\
7 & 0 & -1 & -1 & 2.12 \\
8 & 0 & 0 & 0 & 2.45 \\
9 & 1 & 1 & 0 & 2.48 \\
10 & 0 & 1 & 1 & 2.47 \\
11 & 0 & 0 & 0 & 2.43 \\
12 & 1 & 0 & 1 & 2.41 \\
13 & -1 & 0 & 1 & 2.23 \\
14 & 0 & 0 & 0 & 2.47 \\
15 & 1 & 0 & -1 & 2.25 \\
16 & 0 & 0 & 0 & 2.49 \\
17 & -1 & 1 & 0 & 2.19 \\
\hline
\end{tabular}

The results of significant test and the variance analysis of the model are shown in Table 3 . The three factors (A, B and C) had significant effects on the extraction yield of PRP. Further analysis of the equation variance showed that the model had a higher $F$ value $(F=49.16)$ and a lower $P$ value $(p<0.0001)$, indicating that this model was highly significant. The lack-of-fit $(0.7849)$ was not significant demonstrating that the quadratic polynomial model selected by the study had a high degree of significance. The total determination coefficient of the regression model $\mathrm{R}^{2}=0.9844$ and the adjusted determination coefficient $R^{2}$ adj $=0.9644$, which indicated the model had good fitting degree with small experimental error. Thus, the regression equation model established was valid and could be applied to analyze and predict the extraction conditions of PRP.
The response surface and contour plots of the effects of three factors on the extraction yield of the PRP were obtained according to the multiple regression equation. The response surface and the contour plot are shown in Figure 1. It could be seen from the figure that the interaction between extraction time and number of extraction had a significant effect on the extraction yield of PRP. The yield of PRP was not affected by the interactions between other factors.

The optimal extraction conditions of PRP were as follows: the extraction time was $103.13 \mathrm{~min}$, number of extraction was 2.73 , and the solidliquid ratio of $24.23 \mathrm{~g} / \mathrm{mL}$. The predicted value of extraction yield of PRP was $2.55 \%$. To validate the predicted conditions, the optimal extraction conditions were modified as: extraction time of $103 \mathrm{~min}$, number of extraction of 3 and the solidliquid ratio of $24 \mathrm{~g} / \mathrm{mL}$. The above conditions were used to extract the PRP three times and the mean yield of PRP was $2.47 \%$. Therefore, the optimal extraction conditions of PRP based on RSM were accurate and reliable.

\section{Monosaccharide composition analysis}

HPLC chromatograms of the monosaccharide composition of PRP are shown in Figure 2. The results indicated that PRP was composed of Man, Gal acid, Glc, Gal, and Ara with a molar ratio of $5.76: 2.20: 4.57: 2.64: 1$.

\section{Molecular weight distribution}

The GPC chromatogram of PRP is shown in Figure 3. A standard calibration curve [ $\log (\mathrm{M})=$ - $0.00163 R T+6.712(r=0.9965)]$ was obtained by a series of dextran standards. The calibration

Table 3: Analysis of variance (ANOVA) for the fitted quadratic polynomial model

\begin{tabular}{llllll}
\hline Source & Sum of squares & $\mathbf{d f}$ & Mean square & F -Value & $\boldsymbol{P}$-value \\
\hline Model & 0.39 & 9 & 0.044 & 49.16 & $<0.0001$ \\
$\boldsymbol{A}$ & 0.048 & 1 & 0.048 & 54.21 & 0.0002 \\
$\boldsymbol{B}$ & 0.12 & 1 & 0.12 & 138.21 & $<0.0001$ \\
$\boldsymbol{C}$ & 0.025 & 1 & 0.025 & 28.56 & 0.0011 \\
$\boldsymbol{A B}$ & 0.018 & 1 & 0.018 & 20.56 & 0.0027 \\
$\boldsymbol{A C}$ & $6.250 \mathrm{E}-004$ & 1 & $6.250 \mathrm{E}-004$ & 0.71 & 0.4288 \\
$\boldsymbol{B C}$ & $1.000 \mathrm{E}-004$ & 1 & $1.000 \mathrm{E}-004$ & 0.11 & 0.7468 \\
$\boldsymbol{A}^{\boldsymbol{2}}$ & 0.096 & 1 & 0.096 & 108.30 & $<0.0001$ \\
$\boldsymbol{B}^{\text {2 }}$ & 0.045 & 1 & 0.045 & 50.88 & 0.0002 \\
$\boldsymbol{C}^{\text {2 }}$ & 0.020 & 1 & 0.020 & 22.29 & 0.0022 \\
Residual & $6.205 \mathrm{E}-003$ & 7 & $8.864 \mathrm{E}-004$ & - & - \\
Lack of fit & $1.325 \mathrm{E}-003$ & 3 & $4.417 \mathrm{E}-004$ & 0.36 & 0.7849 \\
Pure error & $4.880 \mathrm{E}-003$ & 4 & $1.220 \mathrm{E}-003$ & - & - \\
Cor total & 0.40 & 16 & - & - & - \\
Std.dev. & 0.9844 & - & - & - & - \\
Mean & 0.9644 & - & - & - & - \\
$\boldsymbol{C V}$ (\%) & 0.9276 & - & - & - & - \\
\hline
\end{tabular}


curves showed good linearity in the range of $1.26 \times 10^{4}$ to $4.96 \times 10^{5} \mathrm{~g} / \mathrm{moL}$. RT, Mw, Numberaverage Molecular Weight $(\mathrm{Mn})$ and relative content of PRP were obtained by using GPC software (Agilent, USA) (Table 4). The results of HPGPC analysis showed that the PRP had a broad $M_{W}$ range. There were six constituents with different molecular weights level in PRP and the average $\mathrm{Mw}$ values were approximately 445065, 329918, 176010, 119024, 99238 and 13592.
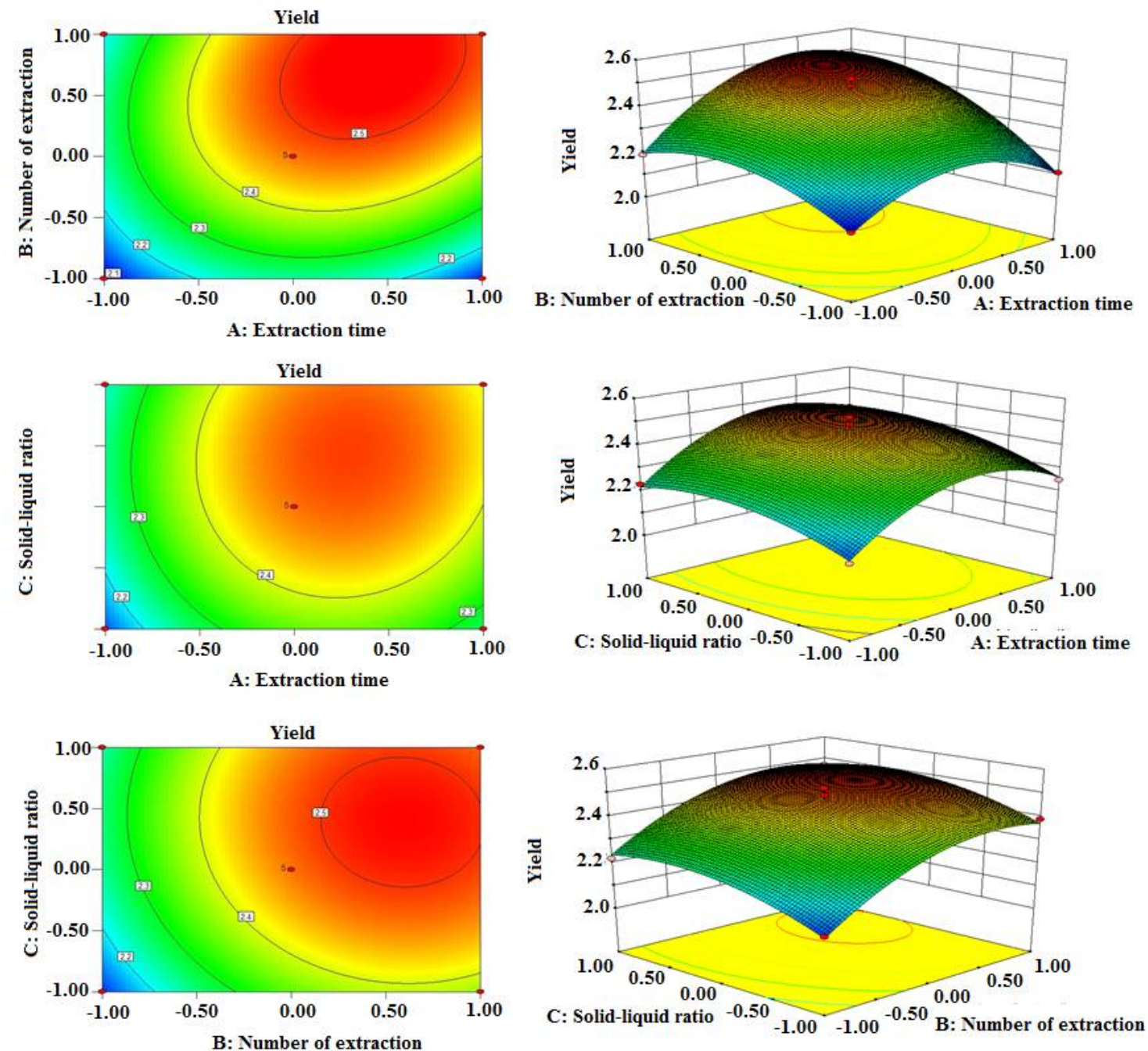

Figure 1: Contour plots and response surface for the yield of PRP

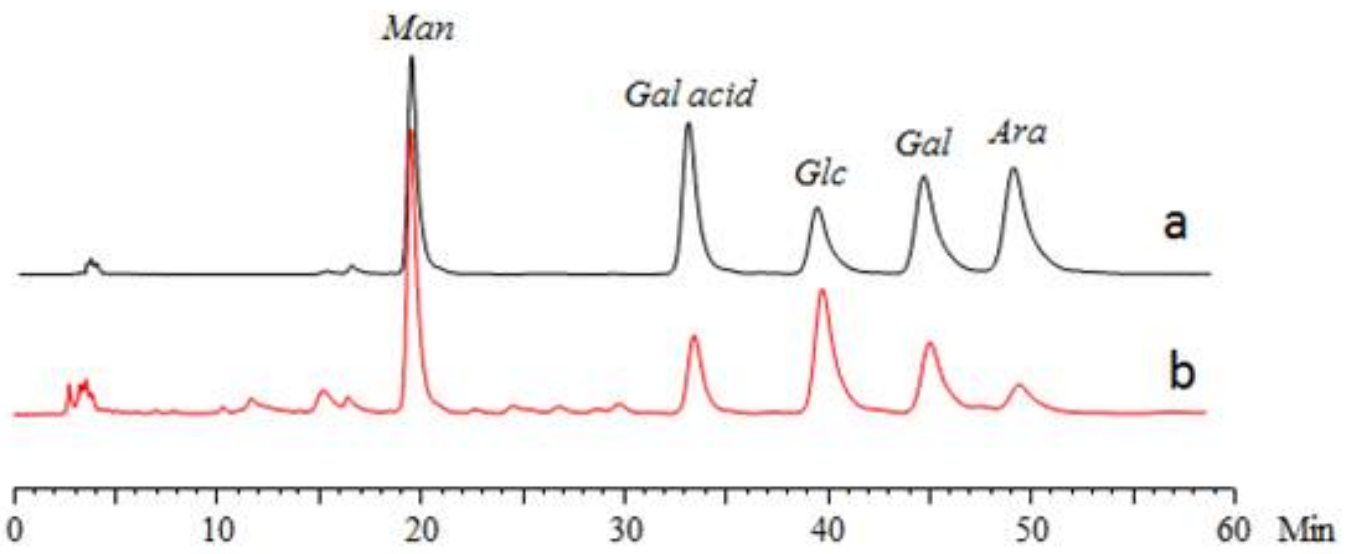

Figure 2: HPLC chromatograms of PMP derivatives of monosaccharide standards (a) and hydrolysate of PRP (b) 


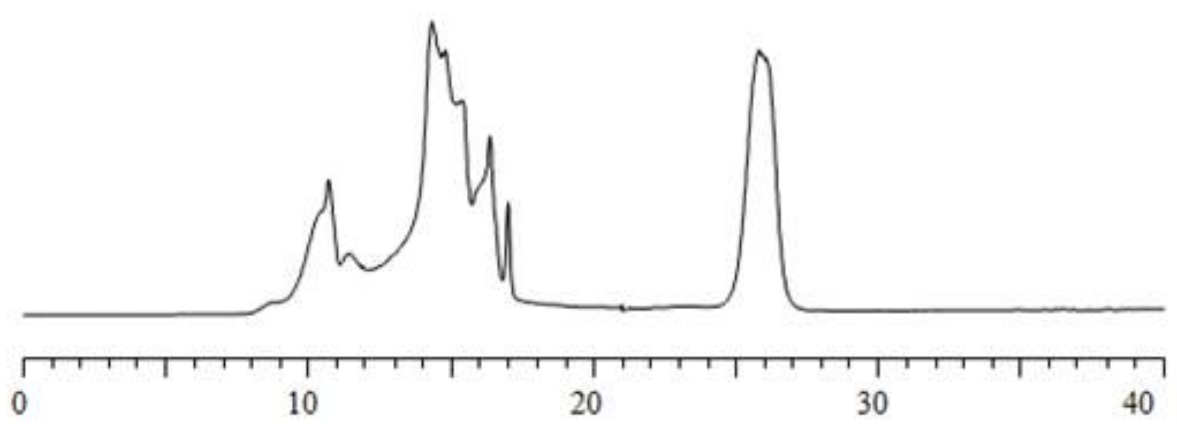

Figure 3: HPGPC-ELSD chromatogram of molecular weight distribution of PRP.

Table 4: Molecular weight distribution of PRP

\begin{tabular}{lccccc}
\hline Peak no. & $\begin{array}{c}\text { Retention } \\
\text { time }(\mathbf{m i n})\end{array}$ & Mw (g/mol) & Mn (g/mol) & Mw/Mn & Relative content (\%) \\
\hline 1 & 11.221 & 445065 & 440830 & 1.010 & 15.83 \\
2 & 12.118 & 329918 & 328425 & 1.004 & 0.66 \\
3 & 18.514 & 176010 & 174895 & 1.006 & 24.43 \\
4 & 19.757 & 119024 & 118561 & 1.004 & 0.13 \\
5 & 20.140 & 99238 & 99156 & 1.001 & 1.56 \\
6 & 26.627 & 13592 & 13454 & 1.010 & 57.38 \\
\hline
\end{tabular}

\section{DPPH radical scavenging effect of PRP}

The results in Figure 4 showed that the antioxidant activity by DPPH radical scavenging assay. The highest scavenging rate of PRP was $71.5 \%$ at a concentration of $10 \mathrm{mg} / \mathrm{mL}$. The 50 $\%$ inhibitory concentration $\left(\mathrm{IC}_{50}\right)$ was calculated by modified Karber's method [23]. As a result, the $\mathrm{IC}_{50}$ of $\mathrm{DPPH}$ radical scavenging activity of PRP was $2.07 \mathrm{mg} / \mathrm{mL}$, while the $\mathrm{IC}_{50}$ of $\mathrm{Vc}$ was $0.024 \mathrm{mg} / \mathrm{mL}$.

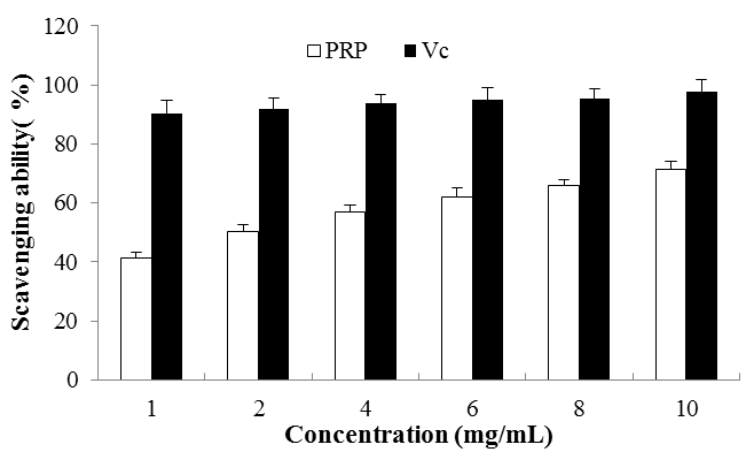

Figure 4: Scavenging effects of PRP on DPPH radicals with $\mathrm{V}_{\mathrm{c}}$ as a positive control. Results are as mean value $(n=3)$

\section{Superoxide anion radical scavenging effect of PRP}

The $\mathrm{O}^{2-}$ free radical scavenging rate of PRP was $87.5 \%$ at the concentration of $10 \mathrm{mg} / \mathrm{mL}$, while that of $\mathrm{Vc}_{\mathrm{c}}$ was $98.7 \%$. The $\mathrm{IC}_{50}$ of $\mathrm{O}^{2-}$ free radical of PRP was $1.37 \mathrm{mg} / \mathrm{mL}$, and that of $\mathrm{Vc}_{\mathrm{c}}$ was $0.044 \mathrm{mg} / \mathrm{mL}$, as shown in Figure 5 . The results indicated that the $\mathrm{O}^{2-}$ scavenging ability of Vc was stronger than PRP.

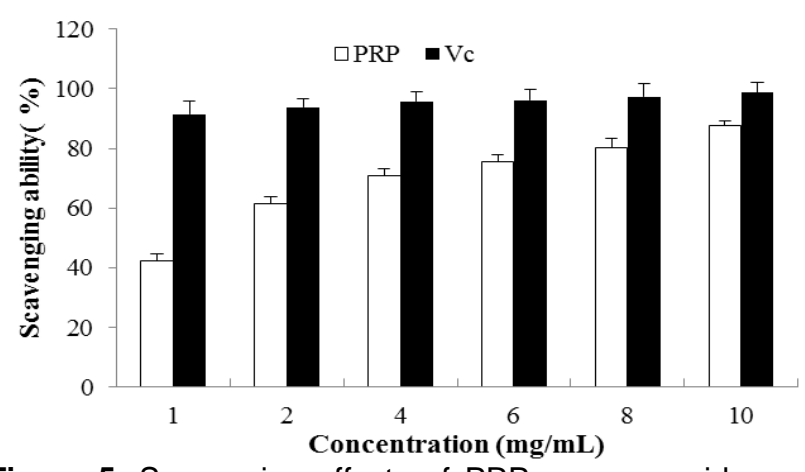

Figure 5: Scavenging effects of PRP on superoxide radicals with $V_{c}$ as a positive control. Data are mean \pm $\mathrm{SD}(\mathrm{n}=3)$

\section{DISCUSSION}

Water extraction method is the most commonly used method for the extraction of plant polysaccharides [24]. Extraction variables have great effects on the extraction yield of polysaccharides. Therefore, it is necessary to optimize the extraction method in order to improve the yield of polysaccharides.

Studies $[25,26]$ have indicated that RSM is an outstanding and effective statistical technique for complex optimization processes by reducing the number of experimental trials compared with traditional methods. Thus, it is widely used to optimize the extraction process of polysaccharides [27]. By employing RSM, the effects of factors on the extraction yield of PRP were achieved by quadratic regression design, and the reliability of the model was validated. 
The results demonstrate that RSM is a rapid and effective statistical technique for PRP extraction.

Monosaccharide composition and molecular weight distribution are two important factors closely related to the activities of natural polysaccharides [28]. In the present study, chemical analysis indicated that the main monosaccharide components of PRP were Man, Gal acid, Glu, Gal, and Ara sugar with a molar ratio of 5.76:2.20:4.57:2.64:1, and the molecular weight ranged from 13592 to 445065 .

It is reported that oxidative stress can result in cell death and tissue damage and cause a large number of diseases, such as cancer, inflammation and ageing, etc. [15]. Polysaccharides extracted from natural materials have been reported to have significant antioxidant activities based on large amounts of antioxidant assays in vitro and in vivo [29]. The present study indicates_that PRP has good antioxidant activities as shown by scavenging DPPH and scavenging superoxide anion radicals data.

\section{CONCLUSION}

RSM is a rapid and effective statistical technique for PRP extraction. Furthermore, PRP has good antioxidant activity, and thus, can potentially be developed as a source of natural antioxidants for the food and pharmaceutical industries.

\section{DECLARATIONS}

\section{Acknowledgement}

This work was supported by National Natural Science Foundation of China (no. 81573610).

\section{Conflict of Interest}

No conflict of interest associated with this work.

\section{Contribution of Authors}

The authors declare that this work was done by the authors named in this article and all liabilities pertaining to claims relating to the content of this article will be borne by them.

\section{Open Access}

This is an Open Access article that uses a funding model which does not charge readers or their institutions for access and distributed under the terms of the Creative Commons Attribution License (http://creativecommons.org/licenses/by/
4.0) and the Budapest Open Access Initiative (http://www.budapestopenaccessinitiative.org/rea d), which permit unrestricted use, distribution, and reproduction in any medium, provided the original work is properly credited.

\section{REFERENCES}

1. Editorial Committee of Chinese Pharmacopoeia. Chinese Pharmacopoeia (2015 ed.). vol. 1. Beijing: China Medical Science and Technology Press; 2015; $p 119$.

2. Zhang $X$, Cai $Y$, Wang L, Liu H, Wang X. Optimization of processing technology of Rhizoma Pinelliae Praeparatum and its anti-tumor effect. Afr Health Sci 2015; 15(1): 101-106.

3. Chen JH, Cui GY, Liu JY, Tan RX. Pinelloside, an Antimicrobial Cerebroside from Pinellia ternata. Phytochemistry 2003; 64(4): 903-906.

4. Kim YJ, Shin YO, Ha YW, Lee SH, Oh JK, Kim YS. Antiobesity effect of Pinellia ternata extract in Zucker rats. Biol Pharm Bull 2006; 29(6): 1278-1281.

5. Wu XY, Zhao JL, Zhang M, Li F, Zhao T, Yang LQ. Sedative, hypnotic and anticonvulsant activities of the ethanol fraction from Rhizoma Pinelliae Praeparatum. J Ethnopharmacol 2011; 135(2): 325-329.

6. Wu J, Cheng Z, He S, Shi J, Liu S, Zhang G, Zhu L, Liu L, Liu Z, Lin N, et al. Pinelliae rhizoma, a toxic chinese herb, can significantly inhibit CYP3A activity in rats. Molecules 2015; 20(1): 792-806.

7. Fu Y, Huang BS, Li J, Tian DZ, Chen KL. Extraction and Isolation of the Protein Components from Pinellia ternata and the Antitumor Activity. Chin J Inform TCM 2007; 14(1): 45.

8. Chen $P$, Li C, Liang $S$, Song $G$, Sun $Y$, Shi $Y$, $X u S$, Zhang J, Sheng S, Yang $Y$, et al. Characterization and quantification of eight water-soluble constituents in tubers of Pinellia ternata, and in tea granules from the Chinese multiherb remedy Xiaochaihu-tang. $J$ Chromatogr B Analyt Technol Biomed Life Sci 2006; 843(2): 183-193.

9. Gonda R, Tomoda M, Shimizu N, Ohara N, Takagi $H$, Hoshino S. Characterization of an acidic polysaccharide with immunological activities from the tuber of Pinellia ternata. Biol Pharm Bull 1994; 17(12): 1549-1553.

10. Tomoda M, Gonda R, Ohara N, Shimizu N, Shishido C, Fujiki Y. A glucan having reticuloendothelial systempotentiating and anti-complementary activities from the tuber of Pinellia ternata. Biol Pharm Bull 1994; 17(6): 859-861.

11. Wang S, Dong $X$, Ma $H$, Cui Y, Tong J. Purification, characterisation and protective effects of polysaccharides from alfalfa on hepatocytes. Carbohydr Polym 2014; 112: 608-614.

12. Li X, Lu P, Zhang W, Li B, Yang R, Luo K. Study on antiEhrlich ascites tumour effect of Pinellia ternata polysaccharide in vivo. Afr J Tradit Complem 2013; 10(5): 380-385. 
13. Zhao YJ, Wang L, Hou L, Zhang XN, Ji ZQ, Yue W. A study on the anti-tumor effect of polysaccharides from pinellia tuber. Chin Pharmaco Bull 2006; 22(3): 368-371.

14. Li Y, Li D, Chen J, Wang S. A polysaccharide from Pinellia ternata inhibits cell proliferation and metastasis in human cholangiocarcinoma cells by targeting of Cdc42 and 67kDa Laminin Receptor (LR). Int J Biol Macromol 2016; 93: 520-525.

15. Hu MB, Peng W, Liu YJ, Wu N, Zhao CB, Xie DS, Yan D, Zhang XF, Tao XB, Wu CJ. Optimum Extraction of Polysaccharide from Areca catechu, Using Response Surface Methodology and its Antioxidant Activity. J Food Process Pres 2016; DOI: 10.1111/jfpp. 12798.

16. Shi Q Q, Dang J, Yue H L, Wen HX, Tao YZ, Wang QL. Isolation, purification and content determination of polysaccharide in Armillaria luteo-rivens mycelium. Ind Microbiol 2015; 45(2): 35-38.

17. Zhang JJ, Zhang QB, Wang J, Shi XL, Zhang ZS. Analysis of the monosaccharide composition of fucoidan by precolumn derivation HPLC. Chin J Oceanol Limnol 2009; 27: 578-582.

18. Kan $Y$, Chen $T, W u Y, W u J, W u J$. Antioxidant activity of polysaccharide extracted from Ganoderma lucidum using response surface methodology. Int $\mathrm{J}$ Biol Macromol 2015; 72: 151-157.

19. Tan LH, Zhang D, Yu B, Zhao SP, Wang JW, Yao L, Cao WG. Antioxidant activity and optimization of extraction of polysaccharide from the roots of Dipsacus asperoides. Int J Biol Macromol 2015; 81: 332-339.

20. Dreher TW, Hawthorne DB, Grant BR. Comparison of open-column and high performance gel permeation chromatography in the separation and molecular weight estimation of polysaccharides. J Chromatogr A 1979; 174: 443-446.

21. Bartolomeuws $S$, Miguel A C, Anai B, Anal P, Joana T M, José $A T$, Manuel $A C$, António $A$ V. Chemical characterization and antioxidant activity of sulfated polysaccharide from the red seaweed Gracilaria birdiae. Food Hydrocolloid 2012; 27(27): 287-292.

22. Wang JL, Zhang J, Wang XF, Zhao BT, Wu YQ, Yao J. A comparison study on microwave-assisted extraction of Artemisia sphaerocephala polysaccharides with conventional method: molecule structure and antioxidant activities evaluation. J Biol. Macromol 2009; 45(5): 483492.

23. Guan SJ, Yan XP, Lin JK. Study on acute toxicity test of different processed products of Radix polygalae. Zhongguo Zhong Xi Yi Jie He Za Zhi. 2012; 32(3): 398401.

24. Yang LQ, Qu HY, Mao GH, Zhao T, Li F, Zhu B, Zhang $B T, W u X Y$. Optimization of subcritical water extraction of polysaccharides from Grifola frondosa using response surface methodology. Pharmacogn Mag 2013; 9(34): 120-129.

25. Hammi KM, Jdey A, Abdelly C, Majdoub $H$, Ksouri $R$. Optimization of ultrasound-assisted extraction of antioxidant compounds from Tunisian Zizyphus lotus fruits using response surface methodology. Food Chem 2015; 184: 80-89.

26. Zhao L, Su C, Zhu B, Jia Y. Development and Optimization of Insulin-Chitosan Nanoparticles. Trop $J$ Pharm Res 2014; 13(1): 3-8.

27. Zhao XJ, Liu JG, Hu YL, Fan YP, Wang DY, Yuan J, Xu $L$, Cui $L$, Jing $Z$. Optimization on condition of glycyrrhetinic acid liposome by RSM and the research of its immunological activity. J Biol Macromol 2012; 51: 299-304.

28. Xia F, Fan J, Zhu M, Tong HB. Antioxidant effects of a water-soluble proteoglycan isolated from the fruiting bodies of Pleurotus ostreatus. J Taiwan Inst Chem E 2011; 42(3): 402-407.

29. Siu KC, Chen X, Wu JY. Constituents actually responsible for the antioxidant activities of crude polysaccharides isolated from mushrooms. J Funct Foods 2014; 11(21): 548-556. 